\title{
NON-DESTRUCTIVE EVALUATION OF THE PULL-OFF ADHESION OF CONCRETE FLOOR LAYERS USING RBF NEURAL NETWORK
}

\author{
Lukasz SADOWSKI \\ Institute of Building Engineering, Wroclaw University of Technology, Wybrzeze Wyspiańskiego 27, \\ 50-370, Wroctaw, Poland
}

Received 28 Sep. 2012; accepted 22 Mar. 2013

\begin{abstract}
The interlayer bond is one of the primary qualities assessed during an inspection of floor concrete workmanship. The measure of this bond is the value of pull-off adhesion $f_{b}$ determined in practice by the pull-off method. The drawback of this method is that the tested floor is damaged in each of the test points and then needs to be repaired. This drawback can be overcome by developing a way which will make it possible to test floors in any point without damaging them locally. In this paper it is proposed to evaluate the pull-off adhesion of the top layer to the base layer in concrete floors by means of the radial basis function (RBF) artificial neural network using the parameters evaluated by the non-destructive acoustic impulse response technique and the non-destructive optical laser triangulation method. Presented RBF neural network model is useful tool in the non-destructive evaluation of the pull-off adhesion of concrete floor layers without the need to damage the top layer fragment from the base.

Keywords: artificial intelligence; concrete floor; interlayer bond; acoustic methods; impulse response technique; surface roughness.

Reference to this paper should be made as follows: Sadowski, Ł. 2013. Non-destructive evaluation of the pull-off adhesion of concrete floor layers using RBF neural network, Journal of Civil Engineering and Management 19(4): 550-560. http://dx.doi.org/10.3846/13923730.2013.790838
\end{abstract}

\section{Introduction}

One of the serious defects occurring in floors is the lack of adhesion at the base layer/top layer interface (Błaszczyński et al. 2006; Łowińska-Kluge, Błaszczyński 2012). Adhesion is the ability of different materials to stick to each other. According to Courard (2000), Fiebrich (1994), Sasse (2007), adhesion proper, connected with chemical and physicochemical interactions (hydrogen bonds an van der Waals bonds), and mechanical adhesion, connected with the mechanical anchoring of the material of one layer in the pores and surface irregularities of another layer, are distinguished. According to Czarnecki and Chmielewska (2005) and Lukowski (2005), the main factors determining the level of adhesion proper are: the compressive strength of the base concrete and the latter's temperature and moisture content. Also, the physical properties of the materials which are to be joined, such as viscosity, wettability, bond shrinkage, thermal expansion and elastic modulus are vital. However, it is the development of the contacting surfaces, the porosity of the substrate and the presence of microcracks in the latter which have the greatest influence on the level of mechanical adhesion. According to
Piotrowski (2009), mechanical adhesion has the decisive influence on the quality of the bond between concrete layers.

The interlayer bond is one of the primary qualities assessed during an inspection of floor concrete workmanship. The measure of this bond is the value of pull-off adhesion $f_{b}$ determined in practice by the pull-off method. The method is both qualitative defects (e.g. no adhesion) at the interface between the layers can be detected - and quantitative - the value of pull-off adhesion $f_{b}$ can be determined. According to this method, adhesion is measured by measuring the ultimate load (pull-off force) using a servomotor with a pressure gauge. For this purpose cores $50 \mathrm{~mm}$ in diameter are drilled in the floor top layer and pulled off (via steel discs stuck onto them) from the surface of the base layer. A value of top layer/base layer adhesion of no less than $0.5 \mathrm{MPa}$ determined in this way is an indicator of good floor workmanship (Courard et al. 2011; Czarnecki, Chmielewska 2011).

The effectiveness of the above semi-non-destructive method to a large extent depends on the number of measuring points. According to standard EN 12504-3:2006, this number should be 1 measurement

E-mail: lukasz.sadowski@pwr.wroc.pl 
per $3 \mathrm{~m}^{2}$ of floor. This requirement is rather onerous in the case of large-area floors, considering that the floor is damaged in each of the measuring points, as shown in Figure 1. Each such damage must be repaired after the test. Consequently, in practice the number of measuring points tends to be reduced. Therefore there is a need for a more effective method devoid of the above drawback, which will make it possible to test the

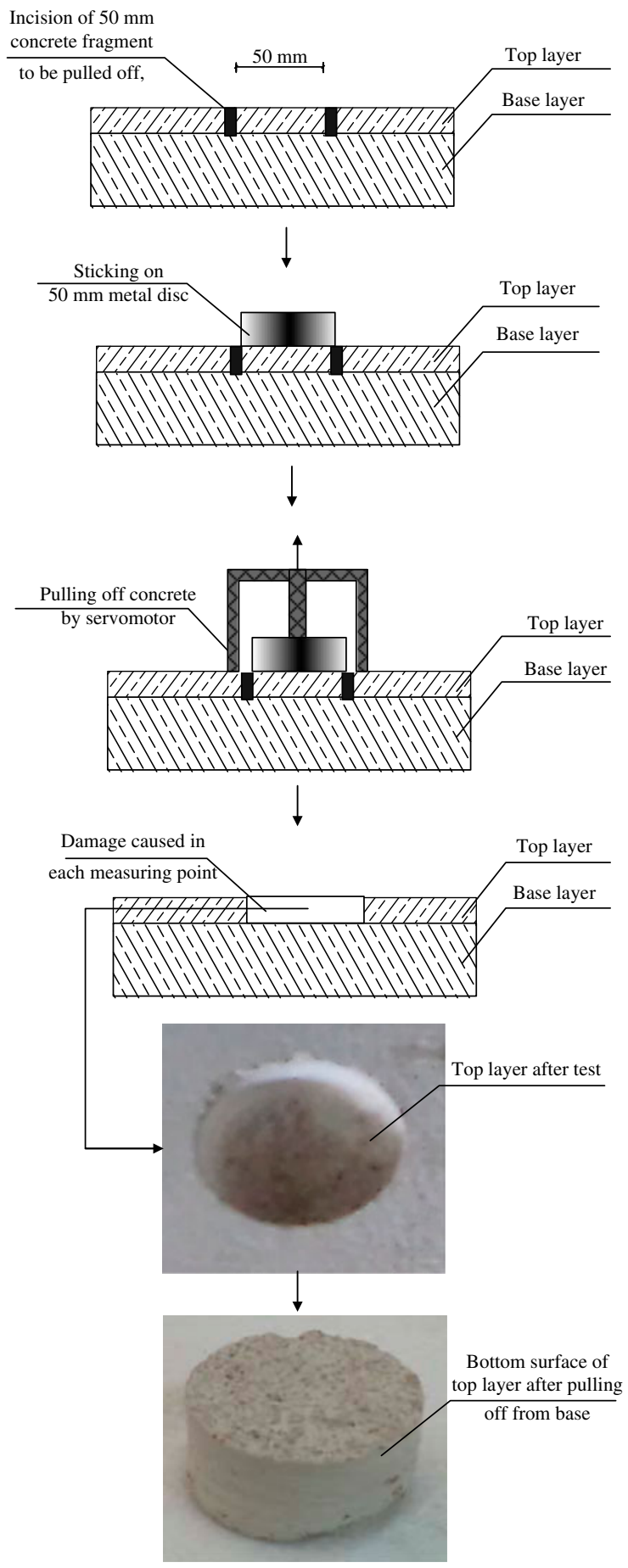

Fig. 1. Sequence showing how floor top concrete layer is damaged by pulling off $\phi 50 \mathrm{~mm}$ piece of it from base, using semi-non-destructive method floor in any place without damaging the tested surface.

The proper preparation of the base layer, which can be described in terms of surface roughness, is a major determinant of pull-off adhesion $f_{b}$ at the interface between the concrete layers in a floor (Kuzinovski et al. 2009; Mathia et al. 2011). It has been demonstrated that there is a correlation between roughness parameters and pull-off adhesion (Garbacz et al. 2006; Naderi, Ghodousian 2012; Siewczyńska 2012). From the point of view of the non-destructive assessment of the quality of the interlayer bond in concrete floors, the surface roughness parameters determined by the non-destructive optical laser triangulation (scanning) method prior to base surface concreting can be useful (Gonzalez-Jorge et al. 2012; Grzelka et al. 2010; Reiner, Stankiewicz 2011). Literature reports indicate that $3 \mathrm{D}$ parameter values determined by analysing the spatial image of the tested concrete surface (Fig. 2) can be used in order to non-destructively assess the interlayer bond in concrete floors. Such parameters as: arithmetical mean height of the surface $S_{a}$, root mean square height of the surface $S_{q}$ or surface bearing index $S_{b i}$ are increasingly often used in civil engineering to describe concrete surface roughness (Grzelka et al. 2011; Ourahmoune et al. 2011; Sadowski 2012; Werner et al. 2013).

Literature reports indicate that also acoustic methods can be useful for assessing the pull-off adhesion of the concrete layers in floors (Beutel et al. 2008; Cerniglia et al. 2010; Gorzelańczyk 2012; Goszczyńska et al. 2012; Hoła, Schabowicz 2010; Matsuyama et al. 2010). As opposed to the seminon-destructive pull-off method, they supply information about the tested element without disturbing its structure. An example of their application can be found in the paper (Hola et al. 2011) dealing with the assessment of the interlayer bond in concrete floors, using the zero/one (no bond/bond) system, in order to identify concrete floor areas in which delamination at the top layer/base layer interface occurred.

From among non-destructive methods, the acoustic impulse response technique is suitable for the considered purpose. The test equipment used in this method is shown in Figure 3. According to the papers (Davis 2003; Hoła, Sadowski 2012; Ottosen et al. 2004), the parameters most useful in this technique are: average mobility $N_{a v}$ and stiffness $K_{d}$. In Hoła and Sadowski (2012) an attempt was made to determine reliable correlations between the individual parameters recorded by the impulse response technique and the pull-off adhesion determined by the pulloff method. However, the attempt was unsuccessful because of the low values of the coefficient of determination. 


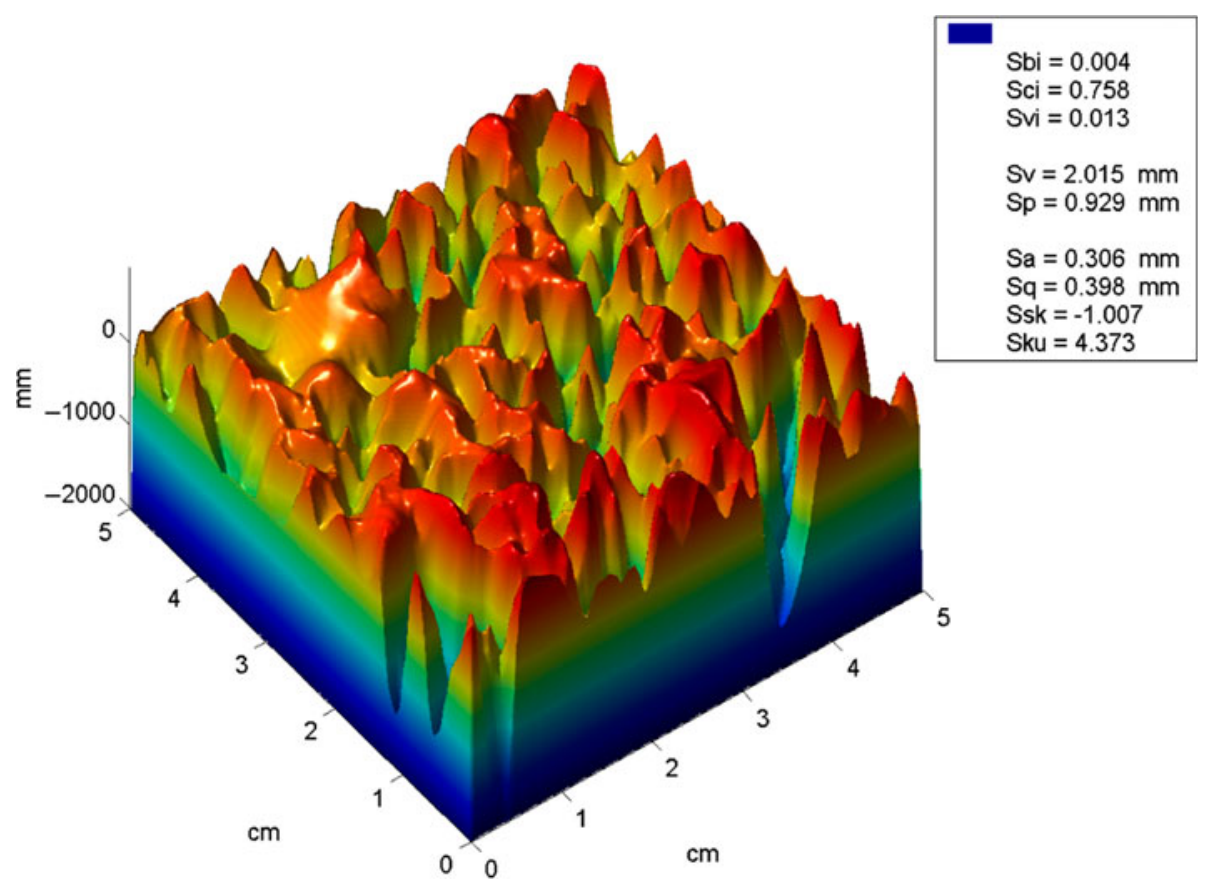

Fig. 2. Typical spatial image of scanned surface, and surface roughness parameters

Considering the above, it seems reasonable to search for a new method of identifying the pull-off adhesion of the concrete layers in floors on the basis of several parameters describing base layer roughness and parameters determined on the surface of the floor top layer by the impulse response technique. In order to correlate a larger number of parameters it was proposed to use artificial neural networks (ANNs) (Kwaśnicka 2005). ANNs have been increasingly often used in civil engineering (Altun et al. 2008; Bilgehan et al. 2012; Gencel et al. 2011; Hasanzadehshooiili et al. 2012; Hoła, Schabowicz 2005; Shaw et al. 2005; Kaczmarczyk, Waszczyszyn 2007; Sadowski 2013;

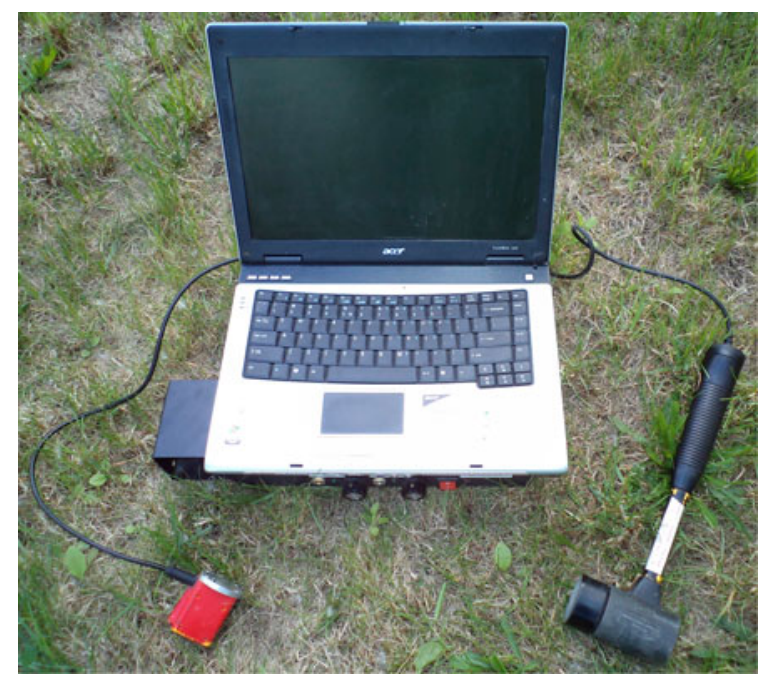

Fig. 3. Test equipment used in non-destructive acoustic impulse response technique
Zapata et al. 2012). One of the most often used ANNs are radial basis function (RBF) ANNs. The advantages they offer are the much simplified selection of the input layer structure and the much simpler and shorter training process requiring less computing power. RBF neural networks have already been applied in civil engineering (Kaliszuk et al. 2001; Kappatos, Dermatas 2007; Kim et al. 2006; Schabowicz 2003; Zhang et al. 2011). They were also used in this research to non-destructively evaluate the pull-off adhesion of the concrete layers in floors on the basis of parameters assessed by non-destructive methods: the optical laser triangulation method and the acoustic impulse response technique.

One can suppose that the parameters in the particular test points on the top layer surface recorded by non-destructive acoustic methods together with the concrete base surface roughness parameters previously non-destructively determined in the same test points, compared with the values of pull-off adhesion $f_{b}$ of the top layer to the base layer determined in the same test points by the semi-nondestructive pull-off method, can make up a database for the training and testing of ANNs. Once an ANN is trained and tested it can be used to generate pull-off adhesion values for any tested area in a given floor on the basis of the parameters recorded using the non-destructive methods.

The aim of this paper is to demonstrate that pulloff adhesion of the top layer to the base layer in any point of a concrete floor can be identified by the RBF neural network on the basis of the base layer surface roughness parameters evaluated by the optical laser triangulation method and the parameters evaluated 
on the floor surface by the acoustic impulse response technique.

\section{Methods used}

In this section the methods used in this research, i.e. the non-destructive impulse response technique, the non-destructive optical technique and the semi-destructive pull-off method, are briefly described. Also the ANN employed is described.

\subsection{Non-destructive impulse response technique}

The non-destructive impulse response technique consists in generating an elastic wave in a tested element by means of a rubber tipped calibrated hammer. The frequency of the generated elastic wave is in a range of $1-800 \mathrm{~Hz}$ and the excitation extends to about $50 \mathrm{~cm}$ around the measuring point. Hammer strikes are executed in selected measuring points. The signal of the elastic wave propagating in the tested element is registered by a geophone and simultaneously amplified by an amplifier. The signals recorded during the tests are subsequently processed using the dedicated Impulse Response s'Mash software installed on a laptop. The measuring set used in the impulse response technique is shown in Figure 4.

The registered parameters are: average mobility $N_{a v}$, stiffness $K_{d}$, mobility slope $M_{p} / N$, average mobility times mobility slope $N_{a v} \cdot M_{p}$ and voids index $v$. Two of the above parameters, which are most often used to locate floor areas lacking adhesion (Hoła, Sadowski 2012), are used in this paper. According to Hoła et al. (2011), Ottosen et al. (2004), they are: $N_{a v}-$ the average mobility of vibrations $N$, defined as a ratio of maximum velocity $w_{\max }$ to maximum elastic wave $F_{\max }$ generated by the hammer:

$$
N_{a v}=\frac{w_{\max }}{F_{\max }} .
$$

$K_{d}$ - the cotangent of mobility curve inclination angle $\alpha$ in a frequency range of $0-80 \mathrm{~Hz}$ :

$$
K_{d}=\operatorname{ctg} \alpha
$$

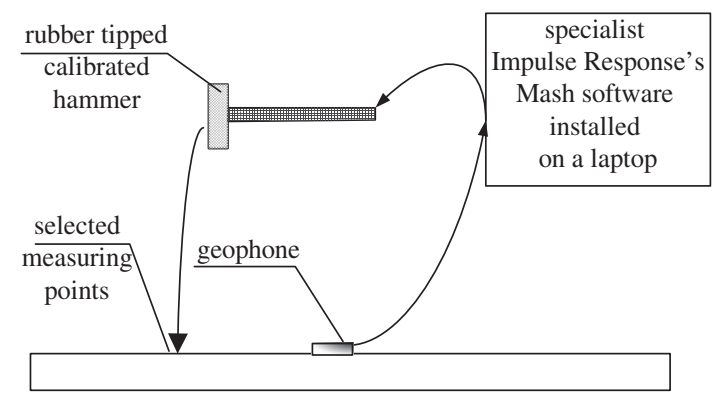

Fig. 4. Schematic of the non-destructive impulse response technique

\subsection{Non-destructive optical technique}

The set for surface roughness examinations by means of the optical technique comprises: a laser distance sensor mounted on a linear drive with a guide, a controller incorporating an amplifier, and a laptop. The IVC Studio 3.1 S.R.2 software installed on the laptop was used in the optical investigations, carried out (in previously determined measuring points) using a $161 \times 55 \times 60 \mathrm{~mm}$ IVC-2D camera with a resolution of $1028 \times 768$ pixels, mounted on a guide (Fig. 5).

Scanning is effected by manually shifting the head above the measuring area during which several surface profiles, separated from one another by a distance of $0.1 \mathrm{~mm}$, are being recorded with a resolution of $0.074 \mathrm{~mm}$. As a result, a 3D image of the concrete surface is obtained. The data from the camera after prefiltration are sent to the laptop to be archived. The dedicated software installed on the laptop is used to process the data and to generate the values of such surface roughness parameters as: $S_{a}$ - the average arithmetic deviation of the surface from reference surface $A$, expressed by the equation:

$$
S_{a}=\frac{1}{A} \sum_{j=1}^{N} \sum_{i=1}^{M} z(i, j),
$$

$S_{q}$ - the rms deviation of the surface from reference surface $A$ :

$$
S_{q}=\sqrt{\frac{1}{A} \sum_{j=1}^{N} \sum_{i=1}^{M} z^{2}(i, j)},
$$

$S_{b i}$ - a surface bearing index, which is a ratio of rms surface roughness deviation $S_{q}$ to $\eta_{0.05}$, where $\eta_{0.05}$ is the level separating the peak surface roughness from the core for a default value of $5 \%$ :

$$
S_{b i}=\frac{S_{q}}{\eta_{0.05}} .
$$

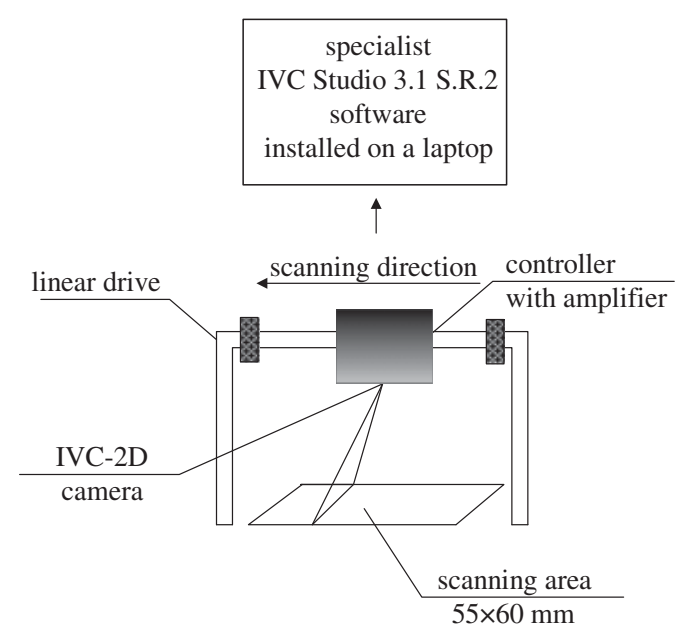

Fig. 5. Schematic of the non-destructive optical technique 
The above three parameters determinable using the non-destructive optical technique were used in this research as the input parameters for training, testing and verifying the ANN.

As part of this research an attempt was made to non-destructively determine pull-off adhesion $f_{b}$ in any measuring point, leaving the surface of the tested concrete floor intact.

\subsection{Semi-destructive pull-off method}

The pull-off method, illustrated in Figure 6, is used to determine the adhesion of concrete floor layers. The method belongs to a group of semi-nondestructive methods. In this method, the adhesion of the top layer to the base layer is evaluated by measuring the pull-off force with a servomotor equipped with a pressure gauge. For this purpose cores $50 \mathrm{~mm}$ diameter are drilled in the topping and pulled off from the base layer.

The method is both qualitative, since it can indicate a defect (e.g. lack of adhesion) at the interface between the layers, and quantitative since using it one can determine pull-off adhesion $f_{b}$.

In this method, $f_{b}$ is calculated from the equation:

$$
f_{b}=\frac{4 \cdot F_{b}}{\pi \cdot D_{f}^{2}}
$$

where: $F_{b}$ - failure load, N; $D_{f}$ - an average sample diameter, $\mathrm{m}$.

\subsection{RBF neural network}

The main purpose of RBF neural networks is to approximate functions of several variables in order to map a set of input variables into a set of output variables (Moody, Darken 1989; Rafajłowicz, Skubalska-Rafajłowicz 2009; Xie et al. 2012; Yao et al. 2012). The approximation in this case is global since it is simultaneously performed for many neurons. In RBF neural networks a hidden neuron executes a function radially changing around a selected centre, assuming nonzero values only in the neighbourhood of this centre, as shown in Figure 7.

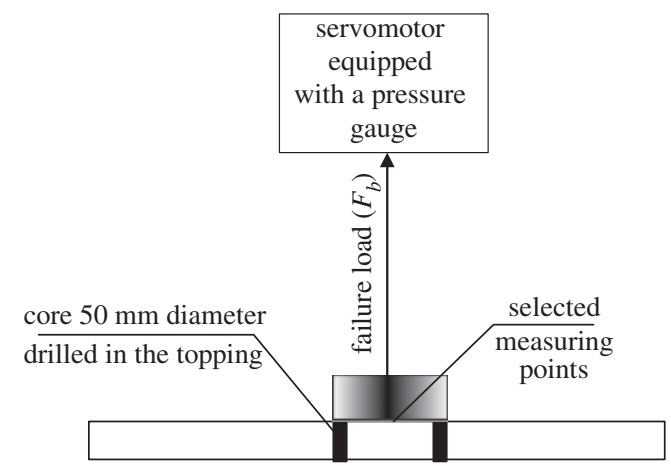

Fig. 6. Schematic of the semi-destructive pull-off method

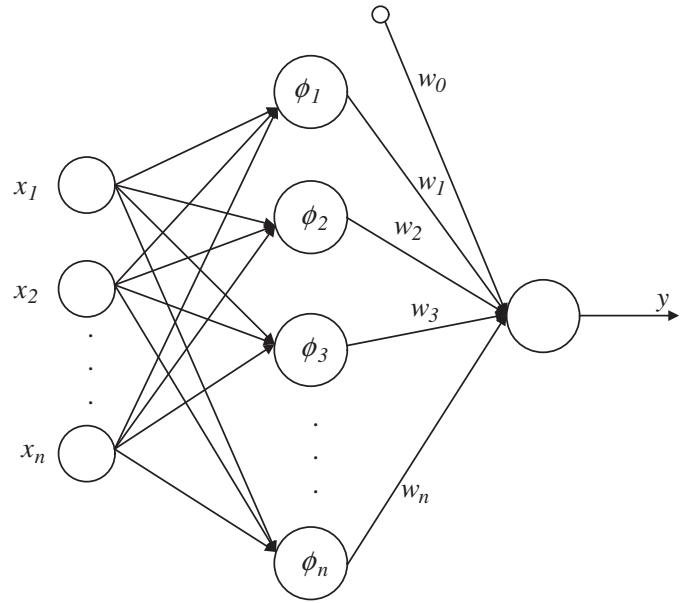

Fig. 7. Schematic of RBF neural network

The effectiveness of a neural network is usually evaluated using such correlation error measures as:

- linear correlation coefficient $R$ :

$$
\frac{R_{i}=\left(P \sum_{p=1}^{P} d_{i}^{p} y_{i}^{p}-\sum_{p=1}^{P} d_{i}^{p} \sum_{p=1}^{P} y_{i}^{p}\right)^{2}}{\left(P \sum_{p=1}^{P}\left(d_{i}^{p}\right)^{2}-\left(\sum_{p=1}^{P} d_{i}^{p}\right)^{2}\right) \cdot\left(P \sum_{p=1}^{P}\left(y_{i}^{p}\right)^{2}-\left(\sum_{p=1}^{P} y_{i}^{p}\right)^{2}\right),}
$$

- relative error (RE):

$$
\mathrm{RE}=\frac{\left|y_{i}^{p}-\overline{y_{i}^{p}}\right|}{y_{i}^{p}},
$$

where: $P$ - the number of training patterns; $M-$ the number of inputs; $d_{i}^{p}-$ the $i^{{ }^{\text {th }}}{ }^{\text {th }}$ expected value for pattern $p ; y_{i}^{p}$ - the $i$-th value of the response from the network to pattern $p ; y_{i-}^{p}$ the average value of the network response to pattern $p$.

\section{Experimental details}

Two $2500 \times 2500 \mathrm{~mm}$ model concrete floor specimens consisting of a $25 \mathrm{~mm}$ thick top layer laid on a $125 \mathrm{~mm}$ thick base were tested. The top layer was made of grade $\mathrm{C} 20 / 25$ cement mortar. The base layer was made of grade $\mathrm{C} 30 / 37$ concrete with a maximum aggregate grading of $8 \mathrm{~mm}$. Up to the time of the tests the specimens had been stored in a laboratory at a temperature of $20 \pm 5{ }^{\circ} \mathrm{C}$. The base layer was laid on a $100 \mathrm{~mm}$ thick layer of sand. The specimens were tested using the non-destructive impulse response technique and the semi-destructive pull-off method after the top layer had cured for 90 days.

Four ways of preparing the base layer surface, denoted with Roman numerals I-IV (Fig. 8) were proposed. The surface of the top layer of each model specimen was marked, a $1500 \times 1500 \mathrm{~mm}$ test area was outlined on the surface and a grid of measuring points 


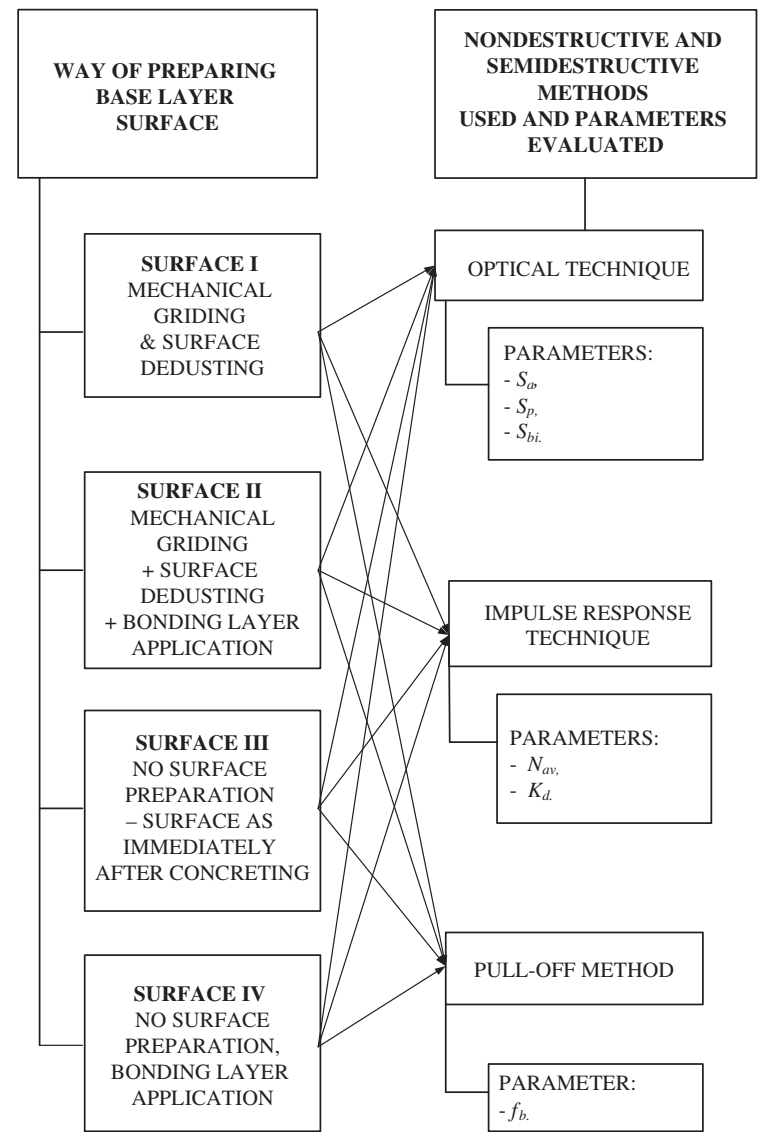

Fig. 8. Combinations of ways of preparing base layer surface and non-destructive and semi-destructive methods with evaluated parameters

spaced at every $100 \mathrm{~mm}$ was marked on it (keeping a minimum distance of $500 \mathrm{~mm}$ from the edge). The columns were denoted with letters from $\mathrm{A}$ to $\mathrm{H}$ and the rows with numbers from 1 to 16 . In total 128 measuring points were marked on each of the surfaces.

The non-destructive impulse response test consisted in generating (with the calibrated hammer) an elastic wave in each point of the measuring grid

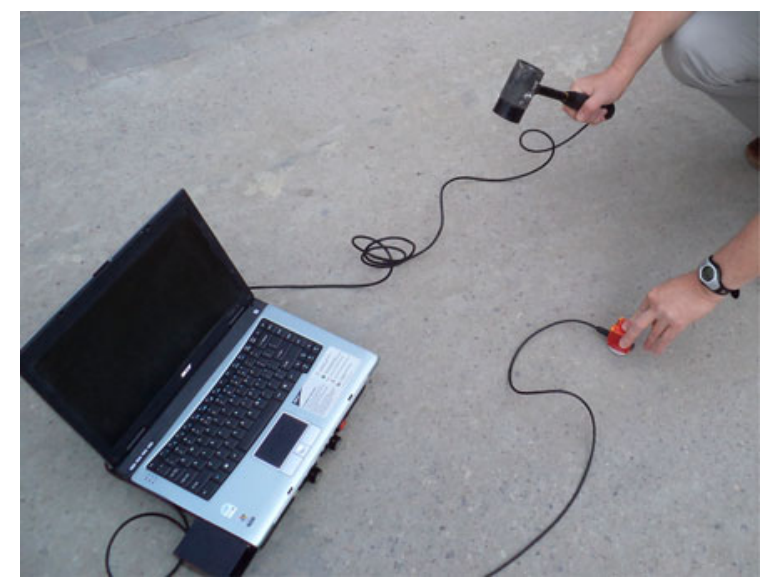

Fig. 9. Testing by means of non-destructive impulse response technique

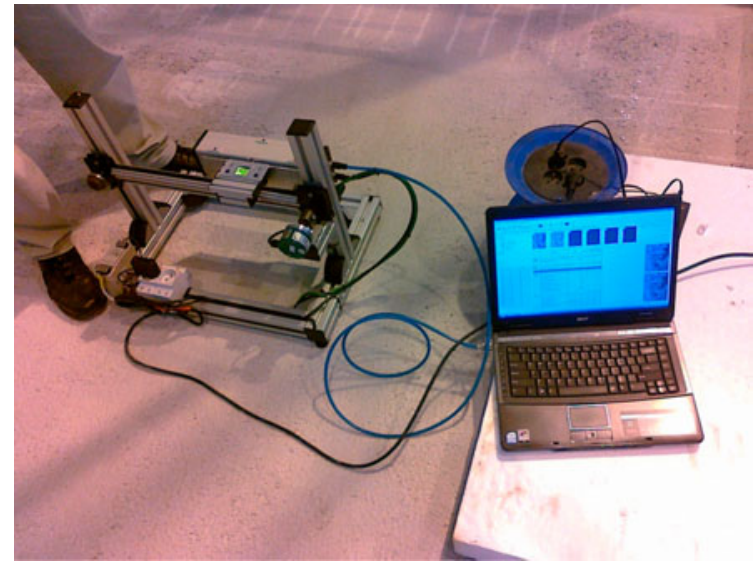

Fig. 10. Testing by means of non-destructive optical technique

marked on the floor's surface (Fig. 9). As a result of the test, the values of characteristic acoustic parameters $N_{a v}$ and $K_{d}$ (their names are given in Fig. 5) in each of the points were obtained.

The non-destructive optical tests consisted in scanning the profiles of a $55 \times 60 \mathrm{~mm}$ base layer from a distance incrementally increasing by $0.1 \mathrm{~mm}$ (Fig. 10). As a result, a 3D image of the concrete surface within the scanned area was obtained. The data were processed using the dedicated IVC Studio 3.1 S.R.2 software installed on the laptop and the values of the concrete surface roughness parameters were displayed.

The semi-non-destructive pull-off tests consisted in determining the adhesion of the top layer to the base layer by measuring the pull-off force by means of a servomotor with a digital pressure gauge. For this purpose $\phi 50 \mathrm{~mm}$ cores were drilled in the top layer in the same points in which previously the optical tests and the impulse response tests had been carried out and the cores were pulled off from the surface of the base layer (Fig. 11).

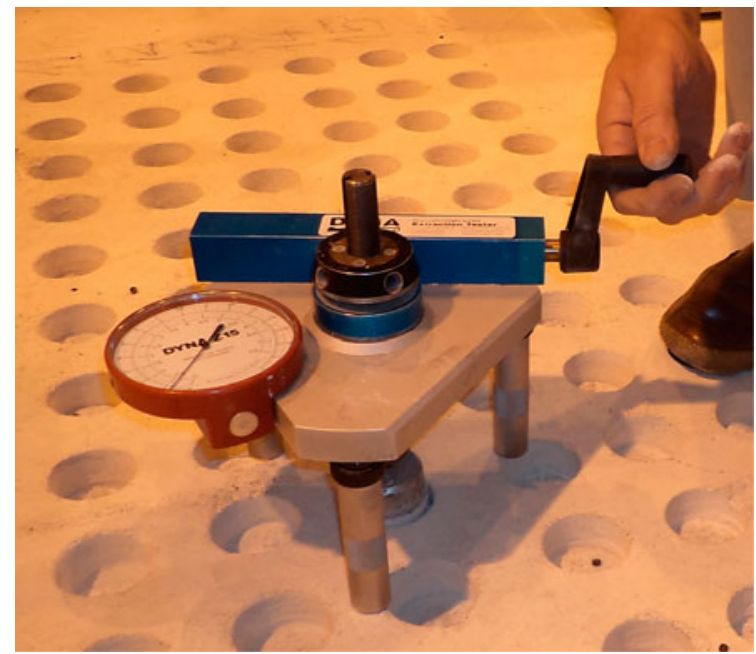

Fig. 11. Testing by means of semi-nondestructive pull-off method 


\section{Database}

The 472 test results were subjected to statistical analysis, whereby the database was reduced to 460 results. The input variables obtained in this way were randomly divided into training data, testing data and verification data. From the 460 input variables, 322 results were selected for training, 69 for testing and 69 for verification. Orthogonal-least-square learning has been used for this purpose. Exemplary test results, determined by the non-destructive impulse response technique, the non-destructive optical technique and the semi-nondestructive pull-off method, used for the training, testing and verification of the ANN are listed in Table 1.

An RBF neural network model with one hidden layer having architecture 5-30-1 was found to be optimal for the non-destructive evaluation of pull-off adhesion (Fig. 12).

\section{Test results and their analysis}

In section 4.1 the results of training and testing the RBF neural network with 30 hidden layer neurons are presented. In section 4.2, the experimental verification of the RBF neural network is described.

\subsection{Results of neural network training and testing}

Figures 13 and 14 show the dependencies between experimentally determined pull-off adhesion $f_{b}$ and pull-off adhesion $f_{c, b}$ identified by the RBF neural network with 30 hidden layer neurons during its training and testing. Thirty hidden layer neurons were selected because for this number RE for training and testing was the lowest and linear correlation coefficient $R$ was the highest. Figures 15 and 16 show bar charts of RE for training and testing.

The dependence between experimentally determined pull-off adhesion $f_{b}$ and pull-off adhesion $f_{c, b}$

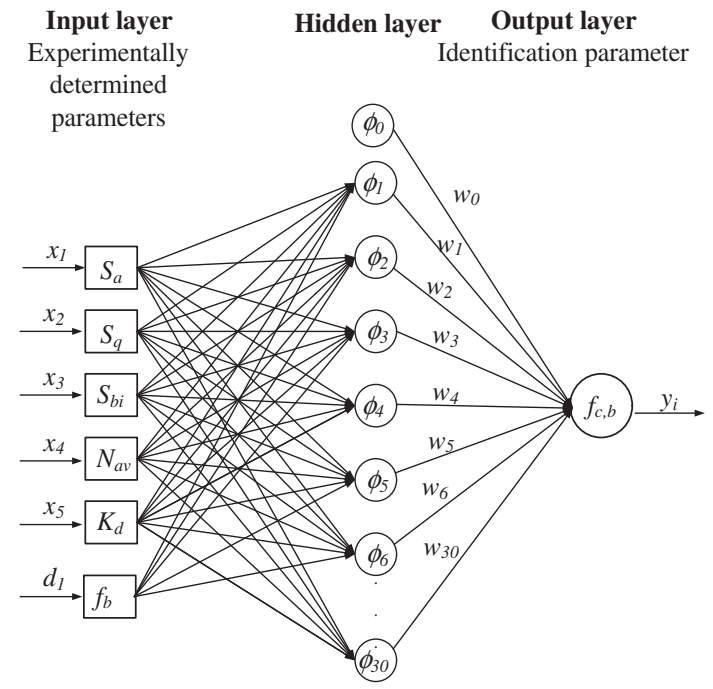

Fig. 12. Schematic of structure of RBF neural network employed for non-destructive evaluation of pull-off adhesion

identified by the neural network during its training is shown in Figure 13. The dependence between experimentally determined pull-off adhesion $f_{b}$ and pull-off adhesion $f_{c, b}$ identified by the neural network during its testing is shown in Figure 14.

The above results show that regardless of the base layer preparation, the RBF neural network correctly maps the training data and correctly identifies the testing data, as evidenced by the location of the points along the regression line corresponding to the ideal mapping. Moreover, high linear correlation coefficients $R$ were obtained for both training and testing: 0.8175 and 0.8225 , respectively, indicating that the fit has a high degree of precision.

Bar charts of RE for pull-off adhesion $f_{b}$ and $f_{c, b}$ for training and testing are shown in respectively Figures 15 and 16. The intervals of RE are marked on the $\mathrm{X}$-axis while the number of results $(n)$ belonging to

Table 1. Exemplary test results selected for training, testing and verification

Measuring techniques with obtained parameters

\begin{tabular}{|c|c|c|c|c|c|c|}
\hline \multirow[b]{2}{*}{ No. } & \multicolumn{2}{|c|}{$\begin{array}{l}\text { Non-destructive impulse } \\
\text { response technique }\end{array}$} & \multicolumn{3}{|c|}{ Non-destructive optical method } & \multirow{2}{*}{$\begin{array}{l}\text { Semi-destructive pull-off method } \\
f_{b}[\mathrm{MPa}]\end{array}$} \\
\hline & $N_{a v}[\mathrm{~m} / \mathrm{s} \cdot \mathrm{N}]$ & $K_{d}[-]$ & $S_{a}[\mathrm{~mm}]$ & $S_{q}[\mathrm{~mm}]$ & $S_{b i}[-]$ & \\
\hline 1 & 83.574 & 0.018 & 0.427 & 0.577 & 0.002 & 0.890 \\
\hline 2 & 106.340 & 0.008 & 0.045 & 0.225 & 0.002 & 0.760 \\
\hline 3 & 109.968 & 0.032 & 0.052 & 0.472 & 0.001 & 0.740 \\
\hline 4 & 108.833 & 0.034 & 0.480 & 0.438 & 0.003 & 0.820 \\
\hline 5 & 72.270 & 0.036 & 0.307 & 0.403 & 0.003 & 0.940 \\
\hline 6 & 63.949 & 0.036 & 0.317 & 0.424 & 0.003 & 0.990 \\
\hline 7 & 49.703 & 0.068 & 0.077 & 0.241 & 0.004 & 1.070 \\
\hline 8 & 51.294 & 0.069 & 0.057 & 0.223 & 0.003 & 1.020 \\
\hline 9 & 43.399 & 0.039 & 0.359 & 0.478 & 0.002 & 1.070 \\
\hline 10 & 70.227 & 0.069 & 0.442 & 0.582 & 0.002 & 1.100 \\
\hline 460 & 61.741 & 0.048 & 0.592 & 0.793 & 0.002 & 0.920 \\
\hline
\end{tabular}




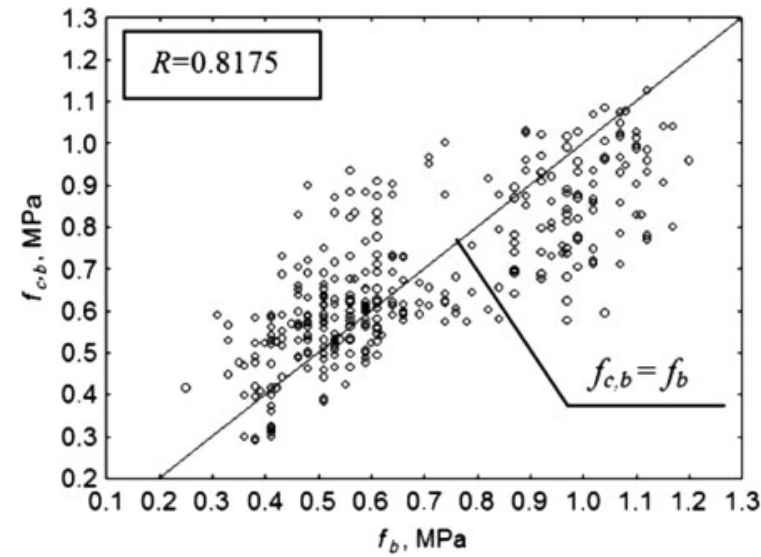

Fig. 13. Dependence between experimentally determined pull-off adhesion $f_{b}$ and pull-off adhesion $f_{c, b}$ identified by neural network during its training

the particular intervals of RE is marked on the Y-axis. According to the figures, most of the RE values are below 0.15 for both training and testing.

Presented results reflect that the RBF neural network output fit very well with the experimental values and as well illustrates that this model possess good interpolation ability.

\subsection{Experimental verification of neural network}

In this section, the experimental verification of the neural network is described. Sixty nine test points were randomly selected. The trained neural network was fed the values of parameters $S_{a}, S_{q}, S_{b i}, N_{a v}$ and $K_{d}$ in each of the 69 measuring points. The trained neural network generated the value of pull-off adhesion $f_{c, b}$ in each of the 69 points. The generated values were compared with the experimental values. Figure 17 shows the dependence between experimentally determined pull-off adhesion $f_{b}$ and pull-off adhesion $f_{c, b}$ identified by the neural network during its verification. The results show that regardless of the

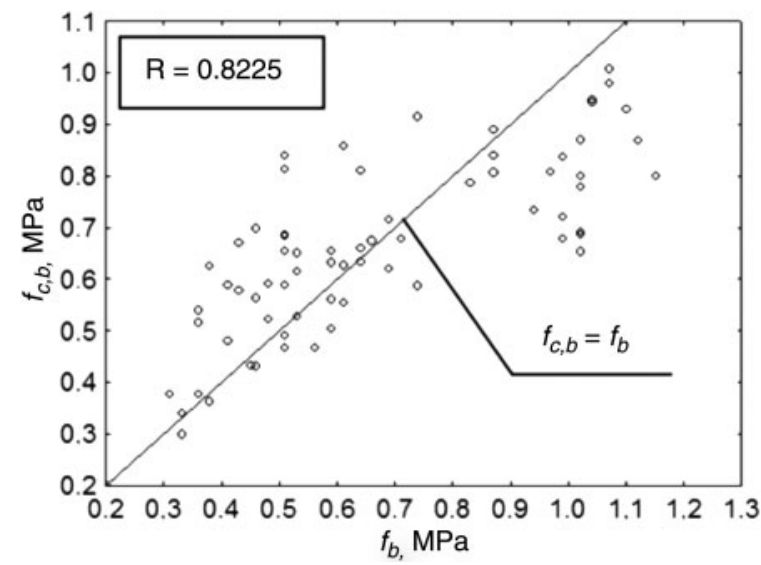

Fig. 14. Dependence between experimentally determined pull-off adhesion $f_{b}$ and pull-off adhesion $f_{c, b}$ identified by neural network during its testing

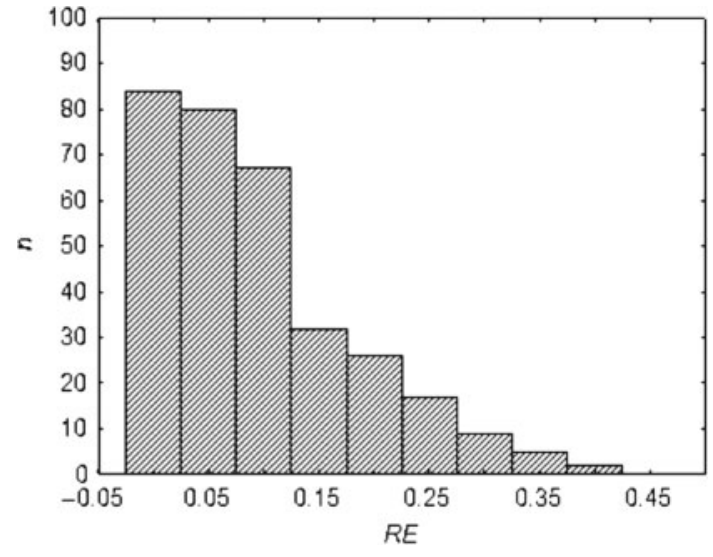

Fig. 15. Bar chart of relative error of pull-off adhesion $f_{b}$ and $f_{c, b}$ for neural network training

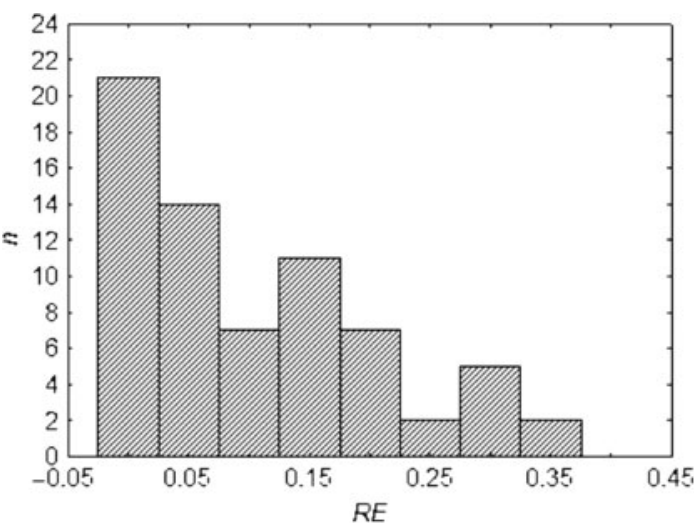

Fig. 16. Bar chart of relative error of pull-off adhesion $f_{b}$ and $f_{c, b}$ for neural network testing

way of preparing the base layer, the neural network correctly maps the randomly selected verification data, as evidenced by the location of the points along the regression line corresponding to the ideal mapping. Linear correlation coefficient $R$ for the experimental

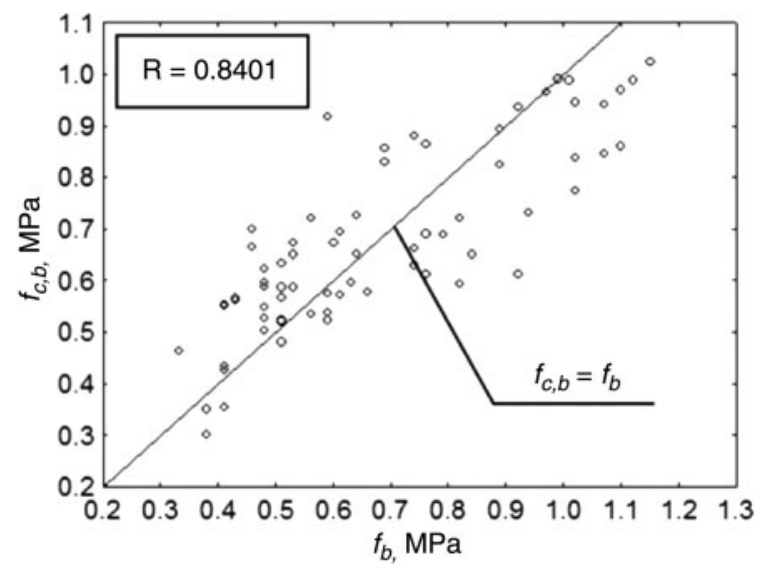

Fig. 17. Dependence between experimentally determined pull-off adhesion $f_{b}$ and pull-off adhesion $f_{c, b}$ identified by neural network during its verification 


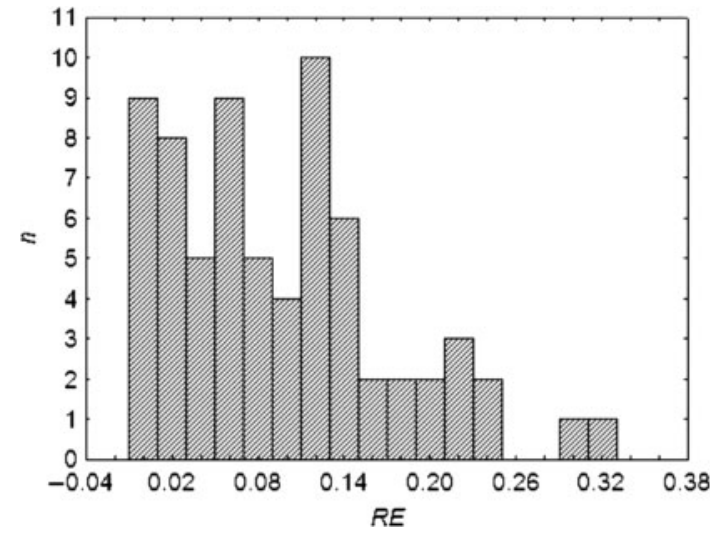

Fig. 18. Bar chart of relative error of pull-off adhesion $f_{b}$ and $f_{c, b}$ for neural network experimental verification

verification of the neural network was found to amount to 0.8401 .

Figure 18 shows a bar chart of RE of pull-off adhesion $f_{b}$ and $f_{c, b}$ for the verification of neural network. The intervals of RE are marked on the $\mathrm{X}$-axis while the numbers $(n)$ of the results belonging to the particular intervals of RE are marked on the Y-axis. The figures show that most of the RE errors for the verification process are below 0.14 .

Conversely, in the RBF neural network verification process, the predicted values of pull-off adhesion $f_{c, b}$ plotted against the experimentally measured values of pull-off adhesion $f_{b}$ indicate that the fit has a very high degree of accuracy.

\section{Conclusions}

The experimental and numerical test results presented in this paper show that the RBF neural network with a properly matched structure and training algorithm is suitable for the non-destructive identification of pulloff adhesion $f_{c, b}$ of the top layer to the base layer in concrete floors on the basis of parameters nondestructively evaluated using the optical laser triangulation method and the acoustic impulse response technique.

The values of this adhesion can be reliably identified by the RBF neural network on the basis of the total of five parameters determined by the nondestructive methods. The parameters are: arithmetical mean height of the surface $S_{a}$, root mean square height of the surface $S_{q}$ or surface bearing index $S_{b i}$ determined on the base layer surface by the optical laser triangulation method, and average mobility $N_{a v}$ and stiffness $K_{d}$, determined on the top layer surface by the acoustic impulse response method. The reliability of the identification is indicated by the high values of correlation coefficient $R$, amounting to $0.8175,0.8225$ and 0.8401 for respectively training, testing and experimental verification, and by the very low values of RE, mostly below 0.15 for training and testing and below 0.14 for verification.

The model based on RBF neural network is useful tool in the non-destructive evaluation of the pull-off adhesion of concrete floor layers without the need to damage the top layer fragment $50 \mathrm{~mm}$ in diameter from the base, which is the main drawback of the pull-off method. However, it should be noted, that the proposed method is not intended to completely replace the semi-non-destructive pull-off method used today to determine the pull-off adhesion of the concrete layers in floors, but it represents a new approach to the neural identification of the values of this adhesion on the basis of five parameters: three describing base layer surface roughness, evaluated by the non-destructive optical laser triangulation method, and two evaluated on the surface of the floor top layer surface by the non-destructive acoustic impulse response technique.

\section{References}

Altun, F.; Kiși, Ö.; Aydin, K. 2008. Predicting the compressive strength of steel fibre addend lightweight concrete using neural network, Computational Materials Science 42(2): 259-265.

http://dx.doi.org/10.1016/j.commatsci.2007.07.011

Beutel, R.; Reinhardt, H.-W.; Grosse, C. U.; Glaubitt, A.; Krause, M.; Maierhofer, C.; Algernon, D.; Wiggenhauser, H.; Schickert, M. 2008. Comparative performance tests and validation of NDT methods for concrete testing, Journal of Non-destructive Evaluation 27(1-3): 59-65. http://dx.doi.org/10.1007/s10921-008-0037-1

Bilgehan, M.; Gürel, M. A.; Pekgökgöz, R. K.; Kısa, M. 2012. Buckling load estimation of cracked columns using artificial neural network modeling technique, Journal of Civil Engineering and Management 18(4): $568-579$.

http://dx.doi.org/10.3846/13923730.2012.702988

Błaszczyński, T.; Jasiczak, J.; Ksit, B.; Siewczyńska, M. 2006. Aspects of bond layer role in concrete repairs, Archives of Civil and Mechanical Engineering 6(4): 75-87.

Cerniglia, D.; Pantano, A.; Montinaro, N. 2010. 3D simulations and experiments of guided wave propagation in adhesively bonded multi-layered structures, NDT \& E International 43(6): 527-535. http://dx.doi.org/10.1016/j.ndteint.2010.05.009

Courard, L. 2000. Parametric study for the creation of the interface between concrete and repairs products, Materials and Structures 33: 65-72. http://dx.doi.org/10.1007/BF02481698

Courard, L.; Lenaers, J.-F.; Michel, F.; Garbacz, A. 2011. Saturation level of the superficial zone of concrete and adhesion of repair systems, Construction and Building Materials 25(5): 2488-2494. http://dx.doi.org/10.1016/j.conbuildmat.2010.11.076

Czarnecki, L.; Chmielewska, B. 2005. Uwarunkowania adhezji w złaczach budowlanych [Factors affecting adhesion in building joints], Cement Wapno Beton 2: 74-85. 
Czarnecki, L.; Chmielewska, B. 2011. Materials and requirements for floor toppings (in Polish), in The 23rd AllPoland Conference on Building Structure Designer's Methodology, Poland, $11 \mathrm{p}$.

Davis, A. G. 2003. The nondestructive impulse response test in North America: 1985-2001, NDT \& E International 36(4): 185-193. http://dx.doi.org/10.1016/S0963-8695(02)00065-8

EN 12504-3:2006 Testing concrete in structures - Part 3: determination of pull-off force. $12 \mathrm{p}$.

Fiebrich, M. 1994. Scientific aspects of adhesion phenomena in the interface mineral substrate-polymers, in Proc. of the 2nd Bolomey Workshop, Adherence of young and old concrete, Aedificato, Verlag, 25-58.

Garbacz, A.; Courard, L.; Kostana, K. 2006. Characterization of concrete surface roughness and its relation to adhesion in repair systems, Materials Characterization 56(4-5): 281-289. http://dx.doi.org/10.1016/j.matchar.2005.10.014

Gencel, O.; Kocabas, F.; Gok, M. S.; Koksal, F. 2011. Comparison of artificial neural networks and general linear model approaches for the analysis of abrasive wear of concrete, Construction and Building Materials 25(8): 3486-3494.

Gonzalez-Jorge, H.; Solla, M.; Armesto, J.; Arias, P. 2012. Novel method to determine laser scanner accuracy for applications in civil engineering, Optica Applicata 42(1): 43-53.

Gorzelańczyk, T. 2012. Acoustically assessed influence of air pore structure on failure of self-compacting concretes under compression, Journal of Civil Engineering and Management 18(1): 60-70. http://dx.doi.org/10.3846/13923730.2011.652982

Goszczyńska, B.; Świt, G.; Trąmpczyński, W.; Krampikowska, A.; Tworzewska, J.; Tworzewski, P. 2012. Experimental validation of concrete crack identification and location with acoustic emission method, Archives of Civil and Mechanical Engineering 12(1): 23-28. http://dx.doi.org/10.1016/j.acme.2012.03.004

Grzelka, M.; Chajda, J.; Budzik, G.; Gessner, A.; Wieczorowski, M.; Staniek, R.; Gapiński, B.; Koteras, R.; Krasicki, P.; Marciniak, L. 2010. Optical coordinate scanners applied for the inspection of large scale housings produced in foundry technology, Archives of Foundry Engineering 49(1): 255-260.

Grzelka, M.; Majchrowski, R.; Sadowski, Ł. 2011. Investigations of concrete surface roughness by means of $3 \mathrm{D}$ scanner, in Proc. of Electrotechnical Institute 58(251): 97-107.

Hasanzadehshooiili, H.; Lakirouhani, A.; Šapalas, A. 2012. Neural network prediction of buckling load of steel arch-shells, Archives of Civil and Mechanical Engineering 12(4): 477-484.

http://dx.doi.org/10.1016/j.acme.2012.07.005

Hoła, J.; Sadowski, Ł. 2012. Testing interlayer pull-off adhesion in concrete floors by means of non-destructive acoustic methods, in The 18th World Conference on Nondestructive Testing, 16-20 April, 2012, Durban, South Africa, 8 p.

Hoła, J.; Sadowski, Ł.; Schabowicz, K. 2011. Nondestructive identification of delaminations in concrete floor toppings with acoustic methods, Automation in
Construction 20(7): 799-807.

http://dx.doi.org/10.1016/j.autcon.2011.02.002

Hoła, J.; Schabowicz, K. 2005. Application of artificial neural networks to determine concrete compressive strength based on non-destructive tests, Journal of Civil Engineering and Management 11(1): 23-32.

Hoła, J.; Schabowicz, K. 2010. State-of-the-art non-destructive methods for diagnostic testing of building structures - anticipated development trends, Archives of Civil and Mechanical Engineering 10(3): 5-18.

Kaczmarczyk, L.; Waszczyszyn, Z. 2007. Identification of characteristic length of microstructure for second order continuum multiscale model by Bayesian neural networks, Computer Assisted Mechanics and Engineering Sciences 14(2): 183-196.

Kaliszuk, J.; Urbańska, A.; Waszczyszyn, Z.; Furtak, K. 2001. Neural analysis of concrete fatigue durability on the basis of experimental evidence, Archives of Civil Engineering 47(3): 327-339.

Kappatos, V. A.; Dermatas, E. S. 2007. Feature extraction for crack detection in rain conditions, Journal of Nondestructive Evaluation 26(2): 57-70. http://dx.doi.org/10.1007/s10921-007-0020-2

Kim, K.-B.; Sim, K.-B; Ahn, S.-H. 2006. Recognition of concrete surface cracks using the ART1-based RBF network, Lecture Notes in Computer Science 3972: 669-675.

Kuzinovski, M.; Tomov, M.; Cichosz, P. 2009. Effect of sampling spacing upon change of hybrid parameters values of the roughness profile, Journal of Production Engineering 12(1): 23-27.

Kwaśnicka, H. 2005. Sztuczna inteligencja i systemy ekspertowe. Rozwój, perspektywy [Artificial intelligence and expert systems. Development and prospects]. Wroclaw: College of Management and Finances. 188 p.

Łowińska-Kluge, A.; Błaszczyński, T. 2012. The influence of internal corrosion on the durability of concrete, Archives of Civil and Mechanical Engineering 12(2): 219-227.

Łukowski, P. 2005. Przyczepność betonopodobnych kompozytów polimerowo-cementowych do podłoża [Adhesion of polymer-cement concretes to the substrate], Cement Wapno Beton 3: 142-147.

Mathia, T. G.; Pawlus, P.; Wieczorowski, M. 2011. Recent trends in surface metrology, Wear 271(3-4): 494-508. http://dx.doi.org/10.1016/j.wear.2010.06.001

Matsuyama, K.; Yamada, M.; Ohtsu, M. 2010. On-site measurement of delamination and surface crack in concrete structure by visualized NDT, Construction and Building Materials 24(12): 2381-2387. http://dx.doi.org/10.1016/j.conbuildmat.2010.05.011

Moody, J.; Darken, C. J. 1989. Fast learning in networks of locally tuned processing units, Neural Computation 1(2): 281-294. http://dx.doi.org/10.1162/neco.1989.1.2.281

Naderi, M.; Ghodousian, O. 2012. Adhesion of selfcompacting overlays applied to different concrete substrates and its prediction by fuzzy logic, The Journal of Adhesion 88(10): 848-865. http://dx.doi.org/10.1080/00218464.2012.705673

Ottosen, N.; Ristinmmaa, M.; Davis, A. 2004. Theoretical interpretation of impulse response tests of embedded 
concrete structures, Journal of Engineering Mechanics ASCE 130(9): 1062-1071.

http://dx.doi.org/10.1061/(ASCE)0733-9399(2004) 130:9(1062)

Ourahmoune, R.; Salvia, M.; Mathia, T.; Berthel, B.; Fouvry, S.; Mesrati, N. 2011. Effect of sandblasting substrate treatment on single lap shear strength of adhesively bonded PEEK and its composites, in The 18th International Conference on Composite Materials, 2011, Jeju, Korea, 6 p.

Piotrowski, T. 2009. Zastosowanie analizy sygnatu impactecho do oceny jakości zespolenia $w$ układach naprawczych betonu [The use of the impact-echo signal to assess bond quality in concrete repair systems]. PhD thesis. Warsaw: Warsaw University of Technology.

Rafajłowicz, E.; Skubalska-Rafajłowicz, E. 2009. RBF nets for approximating an object's boundary by image random sampling, Nonlinear Analysis, Theory, Methods \& Applications 71(12): e1247-e1254. http://dx.doi.org/10.1016/j.na.2009.01.155

Reiner, J.; Stankiewicz, M. 2011. Evaluation of the predictive segmentation algorithm for the laser triangulation method, Metrology and Measurement Systems 18(4): 667-678.

Sadowski, Ł. 2012. Nieniszczaca ocena zespolenia warstw betonowych $w$ podlogach $z$ wykorzystaniem sztucznych sieci neuronowych [Non-destructive evaluation of bond between concrete layers in floors by means of artificial neural networks]. PhD thesis. Wroclaw: Wroclaw University of Technology.

Sadowski, L. 2013. Non-destructive investigation of corrosion current density in steel reinforced concrete by artificial neural networks, Archives of Civil and $\mathrm{Me}$ chanical Engineering 13(1): 104-111. http://dx.doi.org/10.1016/j.acme.2012.10.007

Sasse, H. 2007. Polymer adhesion to concrete - theories and engineering aspects, in Czarnecki, L.; Garbacz, A. Adhesion in Interfaces of Building Materials: a Multiscale Approach, Advances in Materials Science and Restoration, No. 2, Aedificatio Publishers, 7-19.

Schabowicz, K. 2003. Nieniszczaca identyfikacja wytrzymatości na ściskanie betonu z wykorzystaniem sztucznych sieci neuronowych [Non-destructive identification of the compressive strength of concrete by means of artificial neural networks]. $\mathrm{PhD}$ thesis. Wroclaw: Wroclaw University of Technology.

Shaw, M. R.; Millard, S. G.; Molyneaux, T. C. K.; Taylor, M. J.; Bungey, J. H. 2005. Location of steel reinforcement in concrete using ground penetrating radar and neural networks, NDT \& E International 38(3): 203-212. http://dx.doi.org/10.1016/j.ndteint.2004.06.011

Siewczyńska, M. 2012. Method for determining the parameters of surface roughness by usage of a 3D scanner, Archives of Civil and Mechanical Engineering 12(2): 83-89. http://dx.doi.org/10.1016/j.acme.2012.03.007

Werner, S.; Neumann, I.; Thienel, K.-C.; Heunecke, O. 2013. A fractal-based approach for the determination of concrete surfaces using laser scanning techniques: a comparison of two different measuring systems, Materials and Structures 46(1-2): 245-254. http://dx.doi.org/10.1617/s11527-012-9898-y

Xie, T.; Yu, H.; Hewlett, J.; Różycki, P.; Wilamowski, B. M. D. 2012. Fast and efficient second-order method for training radial basis function networks, IEEE Transactions on Neural Networks and Learning Systems 23(4): 609-619. http://dx.doi.org/10.1109/TNNLS.2012.2185059

Yao, W.; Chen, X.-Q; Zhao, Y.; van Tooren, M. 2012. Concurrent subspace width optimization method for RBF neural network modeling, IEEE Transactions on Neural Networks and Learning Systems 23(2): 247-259. http://dx.doi.org/10.1109/TNNLS.2011.2178560

Zapata, J.; Vilar, R.; Ruiz, R. 2012. Automatic inspection system of welding radiographic images based on ANN under a regularisation process, Journal of Nondestructive Evaluation 30(1): 34-45. http://dx.doi.org/10.1007/s10921-011-0118-4

Zhang, G.; Harichandran, S.; Ramuhalli, P. 2011. Application of noise cancelling and damage detection algorithms in NDE of concrete bridge decks using impact signals, Journal of Nondestructive Evaluation 30(4): 259-272. http://dx.doi.org/10.1007/s10921-011-0114-8

Lukasz SADOWSKI. (MSc, Eng), a researcher at Wrocław University of Technology, Poland. He obtained his diploma in civil engineering at WUT in 2007. He is a research assistant at WUT, Institute of Building Engineering. Research interests: concrete (especially concrete floors), non-destructive tests, acoustic techniques and artificial intelligence. 